\title{
RISK ANALYSIS OF THE PILLAR STRENGTH IN THE ESTONIA MINE
} IGAUNIJAS RAKTUVJU STABU STIPRĪBAS RISKA ANALİZE

\author{
Jyri-Rivaldo Pastarus ${ }^{1}$, Sergei Sabanov ${ }^{1}$, Jekaterina Shestakova ${ }^{1}$, Oleg Nikitin ${ }^{2}$ \\ 1- Department of Mining, Tallinn University of Technology \\ 5 Ehitajate tee Str., Tallinn, 19086, Estonia \\ E-mail: pastarus@cc.ttu.ee; sergei.sabanov@ttu.ee; katja.shestakova@gmail.com \\ 2- Eesti Põlevkivi Ltd., Department of Development \\ 10 Jaama Str., Jõhvi, 41533, Estonia; e-mail: oleg.nikitin@ ep.ee
}

\begin{abstract}
This paper deals with the risk analysis and assessment of the pillars strength problems in the Estonia oil shale mine. Aim of this investigation was to determine the strength parameters and predict the bearing capacity of the pillars in Estonia mine, mining block No. 3107

Methods were based on theoretical investigation and experimental data of in-situ conditions. It is given the geological description of the mining block and determined the strength parameters, moisture content and volume density of the oil shale and limestone layers.

Analysis showed that the used risk analysis method is applicable for Estonian oil shale mines. The results of the risk analysis are of particular interest for practical purposes.

Keywords: mining block, pillars, event tree, probability, risk analysis.
\end{abstract}

\section{Introduction}

In Estonia the main mineral resource is a highly calorific oil shale. The deposit is located in a densely populated and rich farming district. The commercially bed typically excavates by underground and surface mining methods. Underground development of oil shale production is obtained by room-and-pillar method with blasting. This method is cheap, highly productive and easily mechanize, but the processes in overburden rocks and pillars have caused unfavorable environmental side effects accompanied by significant subsidence of the ground surface. This is causes a large number of technical, economical, ecological and juridical problems.

The pillars strength is important parameter of mining block stability. For determination pillars strength the experiments in Estonian oil shale mine was made. The strength parameters of in situ conditions were done by Point Load test method. The aim of this investigation is to determine the strength parameters and predict the bearing capacity of the pillars in Estonia mine and to estimate probability of receiving adequate results by the risk analysis method. Analysis of the experimental data showed that it is necessary to modifier the calculation scheme of the pillar parameters.

\section{Geological description and mining system}

The commercially important oil shale bed is situated in the north-eastern part of Estonia. It stretches from west to east for $200 \mathrm{~km}$, and from north to south for $30 \mathrm{~km}$. The oil shale bed lays in the form of a flat bed having a small inclination in southern direction. It depth varies from 5 to $150 \mathrm{~m}$.

The characteristics of the certain oil shale and limestone layers are quite different. The oil shale seams occur among the limestone seams in the Kukruse Regional Stage of the Middle Ordovician. The commercial oil shale bed and immediate roof consists of six oil shale layers (A-F) and limestone (B/A, C/B, D/C, E/D). The main roof consists of carbonate rocks of various thicknesses. The characteristics of various oil shale and limestone seams are quite 
different. The strength of the rocks increases in the southward direction. The compressive strength of oil shale is $20-40 \mathrm{MPa}$ and that of limestone is $40-80 \mathrm{MPa}$. The volume density is $1.5-1.8 \mathrm{Mg} / \mathrm{m}^{3}$ and $2.2-2.6 \mathrm{Mg} / \mathrm{m}^{3}$, respectively. The calorific value of dry oil shale is about $7.5-18.8 \mathrm{MJ} / \mathrm{kg}$ depending on the seam and the location in the deposit

For underground mining the room-and-pillar mining system gives the extraction factor about $80 \%$, and embedded at the depth of $40-70 \mathrm{~m}$. The field of an oil shale mine is divided into panels, which are subdivided into mining blocks, approximately $300-350 \mathrm{~m}$ in width and 600$800 \mathrm{~m}$ in length each. A mining block usually consists of two semi-blocks. The height of the room is $2.8 \mathrm{~m}$ or $3.8 \mathrm{~m}$. The room is very stable when it is $6-10 \mathrm{~m}$ wide. However, in this case the bolting must still support the immediate roof. The pillars in a mining block are arranged in a singular grid. Actual mining practice has shown that pillars with a square cross-section (30$40 \mathrm{~m}^{2}$ ) are best. A work cycle lasts for over a week [1].

\section{Methods of the investigations}

The experiment was made in southern part of Estonia mine, in mining block No. 3107, where the geological conditions are not favorable. Investigation area is located near haulage and collection drifts. Depth of excavation was $59 \mathrm{~m}$ from surface and room height is $3.8 \mathrm{~m}$.

The aim of the tests was to determine the strength parameters of the different oil shale and limestone layers by Point Load test. It is known that the strength parameters of rock depend on moisture content and volume density. Consequently, it is determined these parameters for different layers of in situ conditions.

The Point Load (digital rock strength index apparatus 45-D0550/E), also named Franklin press, is used to obtain quick information concerning rock strength [2]. Point load measurement represents one of the most widely used classification tests for rocks, both in the field and in the laboratory. The test consists to compress up to failure a core or irregular block of rock sample by the application of a point load by a couple of steel conical points of standard size. The point load strength index is calculated using size and shape correction factor. To calculating the average point load strength index, at least 10 point load tests are required. Using the point load strength index it is calculated compressive strength of the rocks. It was determined compressive strength for different layers of oil shale and limestone.

To calculate the strength of an inhomogeneous pillar there is used the formula (pillar containing weak layers) based on experience results [3]:

$$
R=\frac{R_{1}}{1+\left(\frac{R_{1}}{R_{2}}-1\right) \frac{h_{2}}{h}},
$$

where $\mathrm{R}$ - compressive strength of inhomogeneous pillar, MPa;

$R_{1}$ and $R_{2}$ - strengths of the strongest and weakest pillar layers, respectively, MPa;

$h_{2}$ - thickness of the weakest pillar layer, m;

$h$ - pillar height, $\mathrm{m}$.

Moisture content and volume density of samples were determined in laboratory of rock mechanics [3]. For this purpose were extracted the samples from pillar and delivered to laboratory with special action of protection to save originality of samples. For the data processing were used specialized Excel files made at Department of Mining, Tallinn University of Technology.

\section{Results of investigation}

Results of investigations are presented in Table and Figures 1, 2 and 3. Figure 1 showed that limestone has higher compressive strength values $(19.6-63.3 \mathrm{MPa})$ than oil shale one $(4.4-$ 19.6 MPa). Compressive strength of oil shale and limestone layers, received by point load test 
differs from compressive strength received by data of earliest experiments in Estonia mine [4]. It is caused by difference of excavation depth and geological conditions.

Table

Oil shale bed layer parameters

\begin{tabular}{|c|c|c|c|c|}
\hline \multirow{2}{*}{ Index } & \multirow{2}{*}{$\begin{array}{c}\text { Compressive strength, } \\
\text { MPa [4]* }\end{array}$} & $\begin{array}{c}\text { Point Load test } \\
\text { Compressive } \\
\text { strength, } \mathbf{M P a}\end{array}$ & $\begin{array}{c}\text { Moisture } \\
\text { content, } \\
\mathbf{\%}\end{array}$ & $\begin{array}{c}\text { Volumetric } \\
\text { weight, } \mathbf{M g} / \mathbf{m}^{3}\end{array}$ \\
\hline $\mathrm{F}$ & 18 & 19.6 & 6.6 & 1.87 \\
\hline $\mathrm{E}$ & 18 & 6.7 & 8.1 & 1.74 \\
\hline $\mathrm{D} / \mathrm{E}$ & 67 & 19.6 & - & - \\
\hline $\mathrm{D}$ & 29 & 4.4 & - & 1.92 \\
\hline $\mathrm{C} / \mathrm{D}$ & 82 & 63.3 & 4.2 & 2.66 \\
\hline $\mathrm{C}$ & 26 & 9.5 & 12.7 & 1.44 \\
\hline $\mathrm{B} / \mathrm{C}$ & 75 & 48.8 & 5.0 & 2.03 \\
\hline $\mathrm{B}$ & 40 & 9.0 & 8.5 & 1.39 \\
\hline $\mathrm{A} / \mathrm{B}$ & 65 & 27.6 & 4.9 & 2.48 \\
\hline $\mathrm{A}$ & 32 & - & 12.0 & 1.85 \\
\hline
\end{tabular}

* Compressive strength received by data of earliest experiments in Estonia mine.

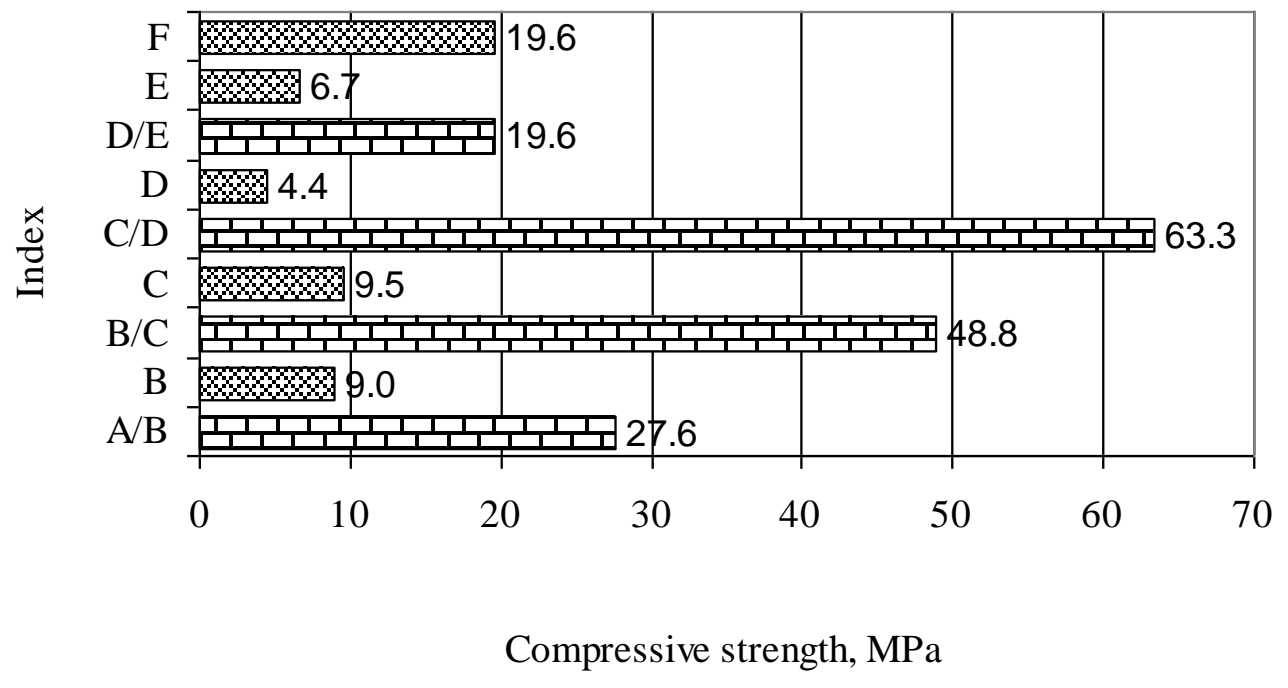

Fig. 1. Compressive strength by Point Load test 


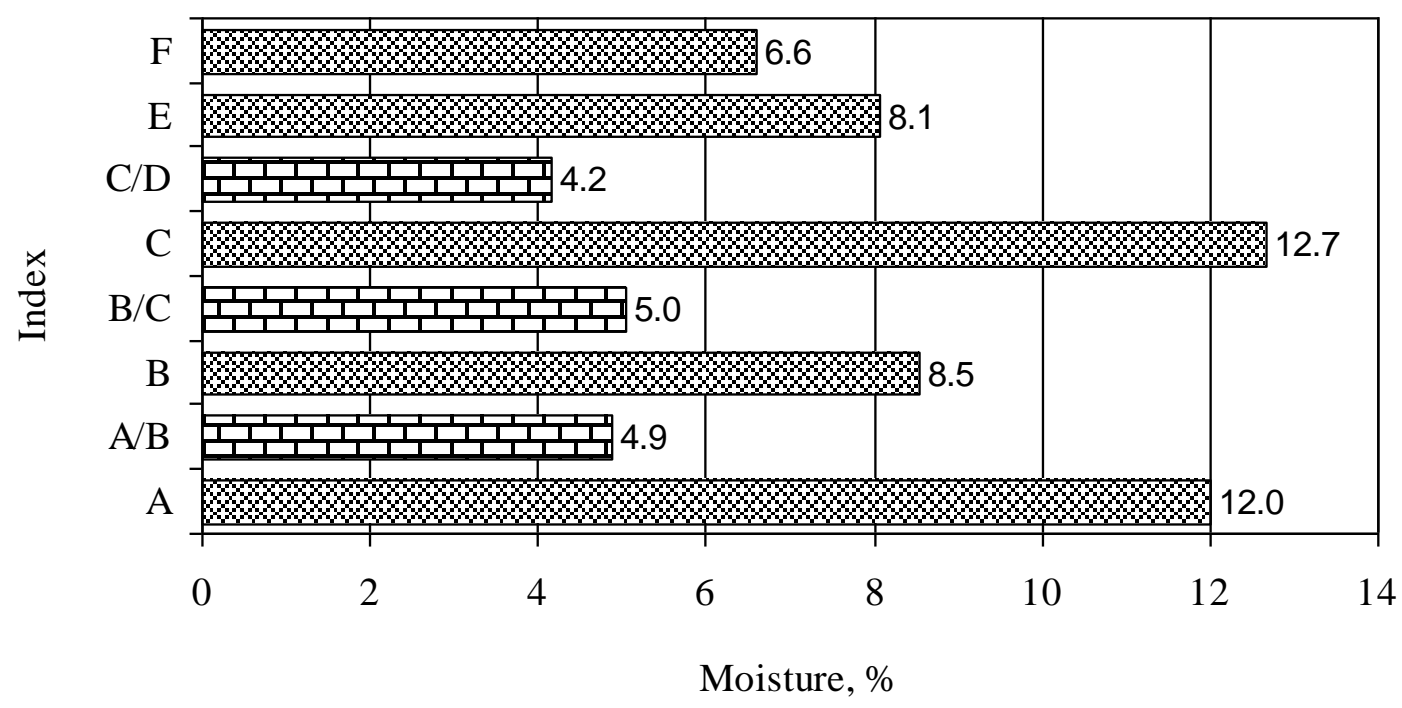

Fig. 2. Moisture content of oil shale bed layers

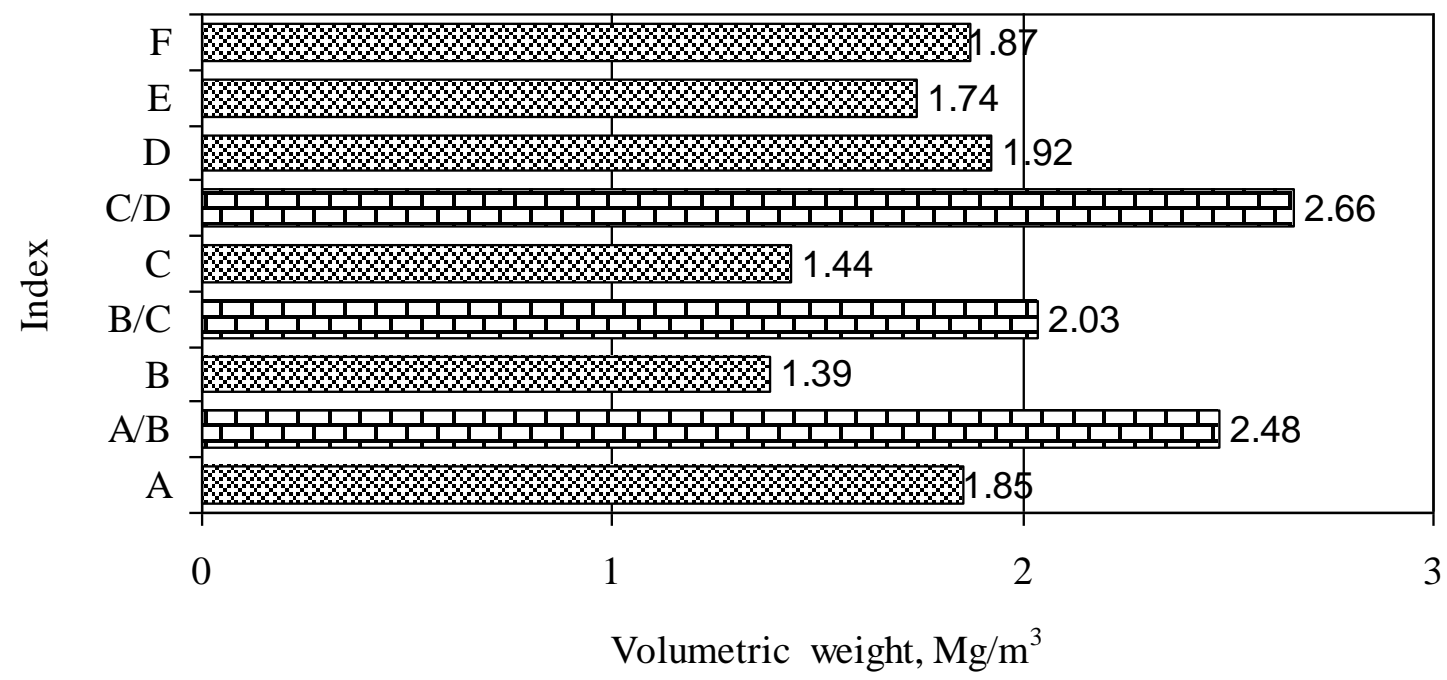

\section{Fig. 3. Volume density of oil shale bed layers}

Investigation showed that moisture content and volume density of layers is different. Moisture content (Figure 2) of oil shale layers varies from 8.1 to $12.7 \%$ and limestone one from 4.2 to $5.0 \%$. The volume density (Figure 3 ) is $1.39-1.87 \mathrm{Mg} / \mathrm{m}^{3}$ and $2.03-2.66 \mathrm{Mg} / \mathrm{m}^{3}$, respectively. Earlier experiments [4] confirm getting results.

Strength parameters of layers and consequently bearing capacity of the pillars depend on geological features in this location, which demand supplementary investigations.

\section{Risk analysis}

By result of calculation using formula (1) the compressive strength of inhomogeneous pillar make 11.6 MPa. This value quit differ from compressive strength using in instructions for calculation the average values of start durability of oil-shale layer in Estonian deposit, which make $16 \mathrm{MPa}$ [5]. For inspection of test result accuracy the risk analysis method with event tree calculation is used. 


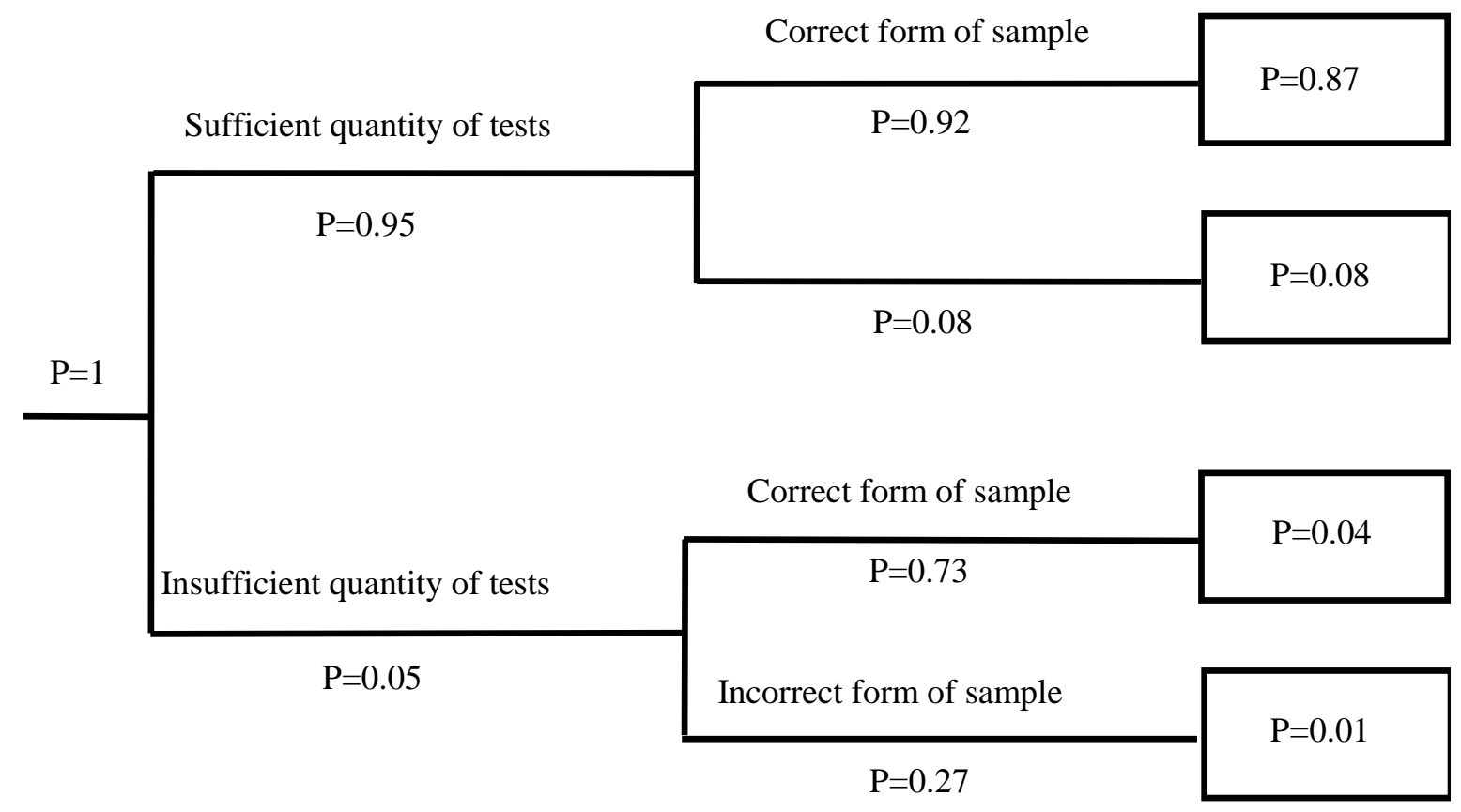

Fig. 4. Event tree

Presented event tree shows probability of receiving adequate results under sufficient quantity of tests and correct form of samples, which is $87 \%(\mathrm{P}=0.87)$. In case under insufficient quantity of tests with correct form of samples the probability makes $4 \%(\mathrm{P}=0.04)$. This result is based on Point Load test, where calculated compressive strength is different from typical parameters based on instruction for calculation of pillars dimensions. Using the event tree, it is possible define probability of receiving adequate results under different quantity of test and various form of the samples and easy to estimate, how every next branch influences on the final result, which could be successfully used in a practice.

\section{Conclusions}

For determination pillars strength the experiments in Estonian oil shale mine was made. The strength parameters of in situ conditions were done by Point Load test method. The strength parameters for the bearing capacity of the pillars in the Estonia mine were determined. By analysis of experimental data the modification of the calculation scheme of pillar parameters is suggested. Risk analysis method used to estimate probability of receiving adequate results under different quantity of test and various forms of the samples.

\section{Acknowledgment}

Estonian Science Foundation (Grant No.6558, 2006-2009) supported the research.

\section{Bibliography}

1. Pastarus J-R., Sabanov S. A method for monitoring mining block stability in Estonian oil shale mines. Proceedings of the Estonian Academy of Sciences. Engineering, 11(1), 2005. pp. 59- 68.

2. 45-D0550/D Digital rock strength index apparatus 2007 (Point Load), Instruction manual.

3. Brady B.H.G., Brown E.T. Rock mechanics for underground mining, Second edition, Kluwer Academic Publishers, 2002. $571 \mathrm{p}$.

4. Nikitin O. Optimization of the Room-and-pillar Mining Technology for Oil-shale Mines, Tallinn, 2003. 73p.

5. Mining-law and legal regulation acts. Ministry of Environment, Ministry of Economy. Part II. Tallinn, 1998. 